\title{
An unusual presentation of COVID-19: Acute pancreatitis
}

\author{
Sathish Kandasamy \\ Department of Imaging Services and Interventional Radiology, \\ G. Kuppuswamy Naidu Memorial Hospital, Coimbatore, India
}

\begin{abstract}
Novel COVID-19 infectious disease typically presents with pulmonary symptoms like cough, shortness of breath, and fever. However, gastrointestinal manifestations of COVID-19 are increasingly being recognized and drawn significant attention. We report an atypical case of acute pancreatitis in a patient with SARSCoV2 infection. CT scan of the abdomen showed findings suggestive of acute interstitial edematous pancreatitis with a CT severity index was 3 . HRCT chest revealed multifocal ground glass opacities in both lungs with a CORADS score of 5. Later, nasal swab for COVID RT-PCR tested positive. The patient was treated symptomatically with fluid replacement, optimization of electrolyte balance and oxygen supplementation. She had an uneventful recovery with gradual resolution of her abdominal and pulmonary symptoms. COVID-19 pathogenesis is believed to be mediated by the angiotensin converting enzyme 2 (ACE-2) receptor over the cell surface. ACE-2, which acts as a receptor for viral entry into host cells are highly expressed in pancreatic cells. All the reported cases of COVID-19 pancreatitis so far are known cases of COVID 19 pneumonia, developed acute pancreatitis or pancreatic injury in due course or during recovery of the illness. Ours is the first case to present with features of acute pancreatitis without any pulmonary symptoms, who turned out to be positive for COVID 19 during workup. Clinicians involved in the management of acute pancreatitis should be aware of its existence in the context of COVID-19. Further studies are needed to establish the real prevalence and clinical significance of pancreatic injury in COVID-19 patients. (Ann Hepatobiliary Pancreat Surg 2020;24:539-541)
\end{abstract}

Key Words: Pancreatitis; COVID-19; Pneumonia

\section{INTRODUCTION}

The current Coronavirus disease 2019 (COVID-19) pandemic is a major challenge for public health and clinical medicine. COVID-19 is caused by severe acute respiratory syndrome coronavirus-2 (SARS-CoV-2), family of single-stranded RNA viruses. COVID-19 typically presents with pulmonary symptoms like cough, shortness of breath, and fever. However, gastrointestinal manifestations of COVID-19 are increasingly being recognized and drawn significant attention. ${ }^{1}$ Although viral acute pancreatitis has been described in other viral infections, pancreatic involvement in SARS-CoV-2 infection is still poorly defined. Herein, we report an atypical case of acute pancreatitis in a patient with SARSCoV2 infection. Clinicians involved in the management of acute pancreatitis should be aware of its existence in the context of COVID-19.

\section{CASE}

A 45-year-old woman was presented to our emergency department with complaints of severe sharp epigastric pain radiating to back for two days, with associated nausea and vomiting. She did not have any history of cough, dyspnea, or fever. The patient denied any history of alcoholism, smoking, and similar complaints in the past. On physical examination, she was afebrile and had tachycardia $(102 \mathrm{bpm})$ with an oxygen saturation of $97 \%$ on room air. Her abdominal examination showed severe epigastric tenderness with a soft, non-distended abdomen. Her laboratory investigations showed elevated serum amylase (364 $\mathrm{U} / \mathrm{L})$ and lipase (293 U/L) levels, WBC of $12.5 \times 10^{3} / \mu \mathrm{L}$, a hemoglobin level of $12.6 \mathrm{~g} / \mathrm{dl}$, and platelets $184 \times 10^{3} / \mu \mathrm{L}$. The liver enzymes including alkaline phosphatase, $\gamma$-glutamyl transferase, alanine transaminase, aspartate amino-

Received: August 1, 2020; Accepted: August 28, 2020

Corresponding author: Sathish Kandasamy

Department of Imaging Services and Interventional Radiology, G. Kuppuswamy Naidu Memorial Hospital, Coimbatore 641037, India Tel: +91-9894384734, Fax: +91-4224305352, E-mail: sathisam@gmail.com

Copyright (C) 2020 by The Korean Association of Hepato-Biliary-Pancreatic Surgery

This is an Open Access article distributed under the terms of the Creative Commons Attribution Non-Commercial License (http://creativecommons.org/ censes/by-nc/4.0) which permits unrestricted non-commercial use, distribution, and reproduction in any medium, provided the original work is properly cited. Annals of Hepato-Biliary-Pancreatic Surgery • pISSN: 2508-5778 - elSSN: 2508-5859 

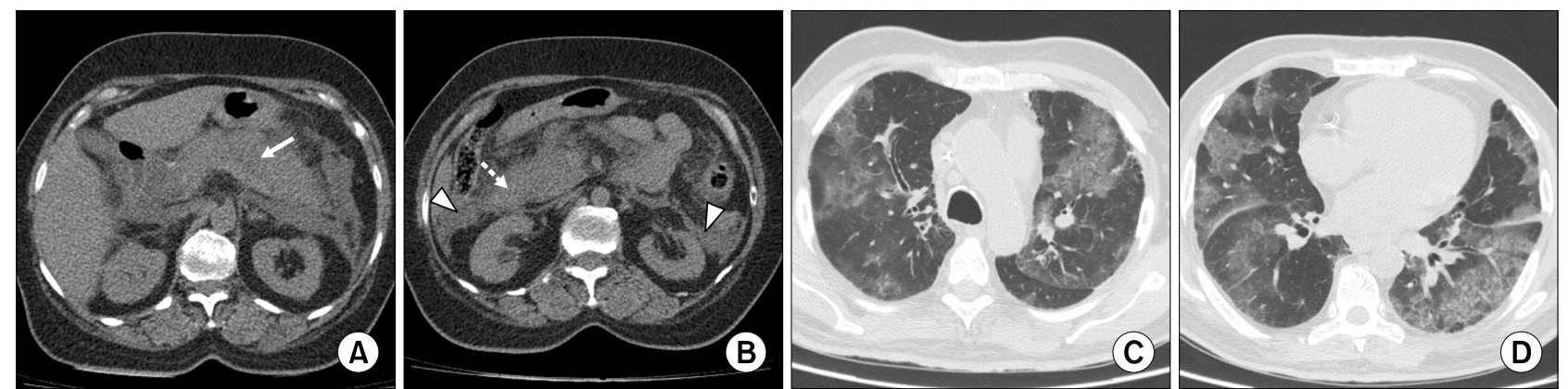

Fig. 1. Non contrast CT scan of the abdomen show (A) diffusely enlarged pancreas (white arrow) with (B) acute peripancreatic (dotted arrow) and pararenal collections (arrow head). HRCT thorax (C, D) show peripherally distributed multi focal areas of ground glass opacities, consistent with CORADS score of 5.

transferase, and total bilirubin were within normal ranges. CT scan of the abdomen showed a diffusely increased volume of the pancreas, with the acute peripancreatic fluid collection and peripancreatic inflammatory changes suggestive of acute interstitial edematous pancreatitis. CT severity index score was 4 (Fig. 1A, B). She was admitted and treated symptomatically with fluid replacement, optimization of electrolyte balance and empiric antibiotics. In the first week, she developed acute hypoxic respiratory failure, with an $\mathrm{SpO} 2$ of 85 percent requiring oxygen supplementation. Her HRCT revealed multifocal groundglass opacities in both lungs, more in the lower lobes with peripheral distribution. These findings were highly suspicious for COVID 19 pneumonia with a CORADS score of 5 (Fig. 1C, D). Later, nasal swab for COVID reverse transcriptase polymerase chain reaction (RT-PCR) tested positive. The patient was isolated and conservatively managed. She had an uneventful recovery with gradual resolution of her abdominal and pulmonary symptoms.

\section{DISCUSSION}

COVID-19 is a novel infectious disease, in addition to pulmonary symptoms can cause a myriad of gastrointestinal symptoms which include mild diarrhea, nausea, vomiting and abdominal pain. ${ }^{1}$ Viral infection is one of the well-known possible etiologies for acute pancreatitis with reported cases due to coxsackie, herpesviruses and hepatitis viruses. ${ }^{2}$ Though there was no direct evidence of viral pancreatitis in this case, we suspect causal relationship between COVID-19 and acute pancreatitis due to their temporal association and lack of other etiologies.

COVID-19 pathogenesis is believed to be initiated by the angiotensin-converting enzyme 2 (ACE-2) receptor over the cell surface. ACE-2, which acts as a receptor for viral entry into host cells are highly expressed in both exocrine glands and islet cells of pancreas, even higher than lung alveolar epithelial cells. ${ }^{3}$ Increased ACE-2 expression may confer increased susceptibility to host cell entry of SARS-CoV-2. Hence, the pancreas might be a potential target cell for SARS-CoV-2 infection. While clear pathogenesis is unknown, pancreatitis in COVID19 could occur due to the direct cytopathic effect of local SARS-CoV-2 replication or indirectly by harmful systemic immune response induced by SARS-CoV-2.

Wang et $\mathrm{al}^{4}$ reported a $17 \%$ incidence of pancreatic damage in a case series of 52 patients COVID-19 patients. Serum markers were mildly elevated, with no cases of abdominal pain or severe pancreatitis. ${ }^{4}$ Liu et al. ${ }^{3}$ also reported a $17 \%$ incidence of pancreatic injury among 67 patients with COVID-19 pneumonia. However, on CT abdomen only $7.46 \%$ cases, showed evidence of pancreatic injury. None of the patients with pancreatic injury presented with abdominal pain or had pancreatic necrosis. ${ }^{3}$ Anand et al. ${ }^{5}$ had reported a recovered case of COVID 19 pneumonia, who was diagnosed with acute pancreatitis based on clinical and imaging findings, five days after the discharge. In a case series of three family members with COVID-19 pneumonia by Hadi et al., ${ }^{6}$ two of them were diagnosed with acute pancreatitis, highlighting the importance of measuring pancreatic enzymes in patients with COVID-19 and abdominal pain.

All the reported cases of COVID-19 pancreatitis so far are known cases of COVID 19 pneumonia, developed acute pancreatitis or pancreatic injury in due course or during recovery of viral pneumonia. Given the temporal 
dissociation, Meireles et al. ${ }^{7}$ presumed that pancreatic involvement likely arises from an immune-mediated inflammatory response rather than a direct viral lesion. However, ours is the first case to present with features of acute pancreatitis without any pulmonary symptoms, who turned out to be positive for COVID 19 during her course of illness. As per revised Atlanta classification, the diagnosis of the acute pancreatitis requires at least two of three following features (a) acute severe abdominal pain suggestive of pancreatitis; (b) serum lipase or amylase level greater than three times of upper normal limit; (c) imaging findings of acute pancreatitis. ${ }^{8}$

Most of the published reports on acute pancreatitis in the context of COVID 19, have diagnosed the pancreatic injury attributing to elevated pancreatic enzymes and the typical abdominal pain. ${ }^{6,79}$ It is vital to make the right diagnosis of acute pancreatitis in COVID-19 patients. Isolated rise in the pancreatic enzymes should not be attributed to pancreatitis without clinico-radiological correlation as such rise can be non-pancreatic in origin and can be seen in other conditions also, especially in the presence of renal or respiratory failure; conditions commonly present in severe COVID-19. ${ }^{10}$ None of the cases reported so far had acute necrotizing pancreatitis even though some were classified as severe, and none required any intervention for pancreatitis related complications. Understanding of the disease process and clinical manifestations of COVID-19 is still developing, and this case demonstrates that SARSCoV-2 can precipitate acute pancreatitis in the setting of COVID-19.

\section{CONCLUSION}

COVID-19 has rapidly spread since its initial identification and has shown a broad spectrum of severity. This report highlights the importance of considering SARS$\mathrm{CoV}-2$ as a new etiological agent of acute viral pancreatitis, especially in this ongoing pandemic. Further studies are needed to establish the real prevalence and clinical significance of pancreatic injury in COVID-19 patients, and underlying pathophysiological mechanisms of the association between COVID-19 and pancreatitis. Awareness of these issues and addressing them adequately will be crucial for the management.

\section{CONFLICT OF INTEREST}

The authors report no conflict of interest.

\section{ORCID}

\author{
Sathish Kandasamy: \\ https://orcid.org/0000-0002-8870-666X
}

\section{REFERENCES}

1. Guan WJ, Ni ZY, Hu Y, Liang WH, Ou CQ, He JX, et al. Clinical characteristics of coronavirus disease 2019 in China. N Engl J Med 2020;382:1708-1720.

2. Kottanattu L, Lava SAG, Helbling R, Simonetti GD, Bianchetti MG, Milani GP. Pancreatitis and cholecystitis in primary acute symptomatic Epstein-Barr virus infection - systematic review of the literature. J Clin Virol 2016;82:51-55.

3. Liu F, Long X, Zhang B, Zhang W, Chen X, Zhang Z. ACE2 expression in pancreas may cause pancreatic damage after SARSCoV-2 infection. Clin Gastroenterol Hepatol 2020;18:2128-2130.e2.

4. Wang F, Wang H, Fan J, Zhang Y, Wang H, Zhao Q. Pancreatic injury patterns in patients with coronavirus disease 19 pneumonia. Gastroenterology 2020;159:367-370.

5. Anand ER, Major C, Pickering O, Nelson M. Acute pancreatitis in a COVID-19 patient. Br J Surg 2020;107:e182.

6. Hadi A, Werge M, Kristiansen KT, Pedersen UG, Karstensen JG, Novovic S, et al. Coronavirus Disease-19 (COVID-19) associated with severe acute pancreatitis: case report on three family members. Pancreatology 2020;20:665-667.

7. Meireles PA, Bessa F, Gaspar P, Parreira I, Silva VD, Mota C, et al. Acalculous acute pancreatitis in a COVID-19 patient. Eur J Case Rep Intern Med 2020;7:001710.

8. Banks PA, Bollen TL, Dervenis C, Gooszen HG, Johnson CD, Sarr MG, et al. Classification of acute pancreatitis--2012: revision of the Atlanta classification and definitions by international consensus. Gut 2013;62:102-111.

9. Aloysius MM, Thatti A, Gupta A, Sharma N, Bansal P, Goyal H. COVID-19 presenting as acute pancreatitis. Pancreatology 2020;20:1026-1027.

10. de-Madaria E, Siau K, Cárdenas-Jaén K. Increased amylase and lipase in patients with COVID-19 pneumonia: don't blame the pancreas just yet! Gastroenterology 2020. doi: 10.1053/j.gastro.2020. 04.044. [in press] 